\title{
Issues in Regulatory Progress of Biosimilars-An Update
}

\author{
Alok Bandyopadhya* \\ Consultant Design Space Inpharmatics, USA \\ Submission: May 05, 2018; Published: June 11, 2018 \\ *Corresponding author: Alok Bandyopadhya, Consultant Design Space Inpharmatics, USA, Email: akbandy@gmail.com
}

\begin{abstract}
In the last ten years bio similar program have progressed significantly both in EU and US. Several products were approved by these Agencies as shown in Table 1. Several submissions are pending to be approved. In the meantime FDA issued two important long waited guidance [13]: one on labeling and the other one in inter changeability of drug product. Several organizations from both countries commented on the labelling and inter changeability [3-5]. According to these comments it is important to provide complete, accurate, transparent prescribing and dispensing information of bio similar and interchangeable biological products [5-9]. If the information is limited about the bio similar product in the labeling for that particular product it is difficult for healthcare providers to prescribe safely and effectively. Several considerations are required to maintain good supply chain reliability and patient support programs. In case of the post-approval requirements, both EMA agree that the post approved biosimilar is not linked to the reference product. Furthermore, any changes to the product have to be evaluated in accordance with the post-approval guidance. The FDA, on the other hand, is working on post-approval guidance for biosimilar products.
\end{abstract}

The above issues are also reflected in a few approved biosimilars. In order to bring more confidence in these biosimilar products new approaches are required to perform post approval research on the safety and effectiveness of biosimilars compared with their branded products.

\section{Introduction}

Biosimilar drugs, which are supposed to be the economical version of branded biotherapeutics, started in getting market approval both in EU and US [1,2]. As the use of biotherapeutics continues to expand within pharmaceutical marketplace, the development of biosimilars represents great potential or vast expansion within the industry. Unfortunately, biosimilar manufacturing is often different from the brand name drug

due to variances in preparation starting from raw materials to finalized products $[3,4]$. As a result, such variations may trigger unwanted adverse events. In this regard US Food and Drug Administration (FDA) issued several draft guidance's. Related to quality consideration, reference product, labeling, and inter changeability in the last three years, shown in Table 1. But still there are a number of issues with biosimilars, which are discussed in this paper.

Table 1: Recently published guidance from FDA.

Considerations in Demonstrating Interchangeability With a Reference Product; Draft Guidance for Industry (PDF-229KB) CDER/CBER, January 2017

Labeling for Biosimilar Products Guidance for Industry (PDF-143KB) CDER/CBER, March 20166

Formal Meetings Between the FDA and Biosimilar Biological Product Sponsors or Applicants; Guidance for Industry (PDF-306KB) CDER/CBER, November 2015

Quality Considerations in Demonstrating Biosimilarity of a Therapeutic Protein Product to a Reference Product; Guidance for Industry (PDF144KB) CDER/CBER, April 2015

Biosimilars: Additional Questions and Answers Regarding Implementation of the Biologics Price Competition and Innovation Act of 2009; Draft Guidance (PDF - 104KB) CDER/CBER, May 2015

Scientific Considerations in Demonstrating Biosimilarity to a Reference Product; Guidance for Industry (PDF-169KB) CDER/CBER, April 2015 


\section{Labeling Issues}

EU guideline states that, the biosimilar's summary of product characterization (SmPC) has to be derived from the reference product [5-7]. According to EMA the information from the reference product's SmPC that applies to biosimilar should be included in the SmPC of the biosimilar. SmPC also refers to detailed information being available in EMA website whereas comprehensive and transparent information of biosimilar is presented in European Public Assessment Reports (EPAR). The critics of this program claim that it does not highlight sufficiently the inherent difference between biosimilars and their reference products. Since they are biological, as discussed earlier $[3,4]$ they cannot be identical with their originals. Instead, a biosimilar has to demonstrate similarity to the reference product in terms of quality characteristics, biological activity, safety, and efficacy based on the comprehensive comparability exercise [8,9].

Implementation of the Biologics Price Competition and Innovation Act ("BPCIA") and subsequently FDA's issuance of the long-awaited draft guidance on labeling of biological products licensed under section 351(k) of the Public Health Service Act (42 USC 262(k)) is a significant event [10].

FDA issued guidance [10], which includes the data and information related to the reference product instead of the information about the biosimilar. According to FDA the data from clinical studies, which support biosimilarity, are not likely to be relevant to a health care practitioner's consideration regarding safe and effective use of the biosimilar product. Several organizations including BIO comment that it is important to provide complete, accurate, transparent prescribing and dispensing information of biosimilar and interchangeable biological products [11].

If the information is limited about the biosimilar product in the labeling for that particular product it is difficult for healthcare providers to prescribe safely and effectively for an individual patient, as well as for formulary and other decision makers who mainly depend on the label to determine the use of the biosimilar. If multiple biosimilars are approved for the same reference product and each has been approved based upon its own unique bio similarity data, the patients and the prescribers should have access to all important information, including the nonclinical and clinical data which will allow to understand how the data were collected.

FDA proposes that the biosimilar product conform to the requirements of the Physician Labeling Rule (PLR) and Pregnancy and Lactation Labeling Final Rule (PLLR), regardless of whether the reference product is required to meet the PLR and PLLR requirements at the time of licensure of the biosimilar product10Several organization including BIO are concerned that requiring the biosimilar product labeling to conform to content and format requirements which do not apply to its reference product may result in confusion to prescribers and patients [9$11]$.

Moreover, updates to the PLR or PLLR format and content may require input of the reference product sponsor. Therefore, the guidance should provide that the biosimilar label be approved consistent with the same PLLR format and content labeling requirements as applicable currently to the reference product and be updated when the reference product label is modified to conform to the new implementation requirements $[10,11]$.

\section{Demonstrating Inter Changeability}

The US has a somewhat different approach for establishing inter changeability compared to Europe. FDA has jurisdiction to classify biosimilars as 'interchangeable', and this designation then enables substitution at the pharmacy level without the consent of the prescribing physician - provided that state legislature permits such substitution and that the prescribing physician has not indicated in the prescription form that the prescribed product must not be substituted [12].

FDA, in its draft guidance [12], recommended "switching" studies, which rotate patients between the biosimilar and the reference product multiple times and monitor the patient's response for any differences with the use of two drugs. FDA has taken in consideration the issues that can be raised from the container-closure, storage condition and the method of application for the drug. The purpose of this consideration is to provide confidence to the patients and their doctors with regard to safety and efficacy of the interchangeable biosimilar.

Some may disagree with the FDA's preference for using U.S. products in the studies required to show that the patient can switch from the original biologic to the biosimilar safely and with no loss of efficacy [13]. Further they think that the draft guidance should discuss the labeling and naming of interchangeable biosimilars. The US biosimilar pathway does not define the amount of data required for interchangeable biosimilar product which 'can be expected to produce the same clinical result as the reference product in any given patient' and 'the risk in terms of safety or diminished efficacy of alternating or switching between use of the biological product and the reference product is not greater than the risk of using the reference product without such alternation or switch' $[10,11]$.

\section{Post-Marketing Issues}

In case of the post-approval requirements, EMA agree that the post approved biosimilar is not linked to the reference product6. Furthermore, any changes to the product have to be evaluated in accordance with the post-approval guidance. If needed, the sponsor may use a "quality-by-design (QbD)" approach to the development of biosimilar products to meet compliance and reduce any post-approval changes16. The FDA, on the other hand, is working on post-approval guidance 


\section{Current Trends in Biomedical Engineering \& Biosciences}

for biosimilar products. It's also important for the FDA to provide specific recommendations about how interchangeable biosimilars should be named and what kind of information should be included on their labels.

As mentioned earlier, EMA permits biosimilars to use same active ingredient (API) name as their brand name counterpart. On the contrary, US naming is not final, but in the interim they are adding a suffix like Sandoz "sndz" for Filgratism biosimilar. This may help both patients and prescribers to distinguish biosimilars. But this may add some confusion later when the different versions of the same API will be in the market. "For reimbursement of provider-administered biologics, payers customarily require a Healthcare Common Procedure Coding System "J code". The Centers for Medicare and Medicaid Services is currently considering requiring unique J codes for biosimilars under Medicare Part B. It should be strongly encouraged to do so; private payers would follow suit, and the requirement would facilitate rigorous, product-specific surveillance of biologics through the FDA>s Sentinel system" [14].

\section{Conclusion}

The issues as discussed above are reflected in the number of approved biosimilars. In order to bring more confidence in these biosimilar products new approaches are required to perform post approval research on the safety and effectiveness of biosimilars compared with their branded products.

\section{References}

1. Siegel JF, Royzman I (2017) Biosimilar approvals in Europe. Biologics Blog.

2. Biosimilars (2018) Biosimilar Product Information-FDA.

3. Bandyopadhyay (2011) A Issues on follow on biologics in regulatory pathway. Regulatory Focus 4(3): 36-43.

4. Bandyopadhyay (2015) A Complexities of protein therapeutics and immunogenicity J Bioanal Biomed 7(3): 70-74.

5. Guideline on similar biological medicinal products, European.

6. Guideline on similar biological medicinal products containing.

7. QRD general principles regarding the SmPC information for a generic

8. Milma S (2015) Labeling of Biosimilars Biopharm Intl 38(2): 12-14.

9. Watson K (2014) Generics and Biosimilars Journal 3(4).

10. Labeling for Biosimilar Products Guidance for Industry (PDF-143KB).

11. (2016) BIO comments on FDA draft guidance labeling for biosimilars.

12. Considerations in demonstrating Inter changeability with a reference product. Draft guidance for Industry (PDF-229KB).

13. Pharmaceutical Development (2009) ICH guideline Q8 (R2).

14.(2017) Biosimilar trends report shows significant progress and challenges.
Your next submission with Juniper Publishers will reach you the below assets

- Quality Editorial service

- Swift Peer Review

- Reprints availability

- E-prints Service

- Manuscript Podcast for convenient understanding

- Global attainment for your research

- Manuscript accessibility in different formats ( Pdf, E-pub, Full Text, Audio)

- Unceasing customer service

Track the below URL for one-step submission https://juniperpublishers.com/online-submission.php 